\title{
Reação de cultivares de alface a Thielaviopsis basicola
}

\author{
Fernando C Sala ${ }^{1}$; Cyro P da Costa ${ }^{2}$; Liliane de D Teixeira ${ }^{2}$; Eliane G Fabri ${ }^{3}$; Sally F Blat ${ }^{4}$ \\ ${ }^{1}$ Tecnoseed, Av. 21 de abril 1432, 98700-000 Ijuí-RS; ${ }^{2}$ USP/ESALQ, C. Postal 9, 13418-900 Piracicaba-SP; ${ }^{3}$ Instituto Agronômico \\ Campinas, C. Postal 28, 13012-970 Campinas-SP; ${ }^{4}$ APTA-Regional Centro Leste, C. Postal 271, 14001-970 Ribeirão Preto-SP; \\ fcsala@terra.com.br
}

\section{RESUMO}

A alface é a folhosa de maior importância no Brasil. O presente trabalho visou determinar a reação de cultivares de alface à murchadeira provocada pelo fungo Thielaviopsis basicola, na fase juvenil. Um experimento foi conduzido em casa-de-vegetação em delineamento inteiramente casualizado, em esquema fatorial 37 x 2 (cultivares, com e sem inoculação), com três repetições. Mudas com 30 dias foram transplantadas para bandejas de 128 células preenchidas com 1/3 de substrato colonizado com 7,5 x $10^{5}$ conídios/g de substrato. Logo após o transplante, inoculou-se $3 \mathrm{~mL}$ de suspensão de esporos de concentração $2 \times 10^{6}$ conídios $/ \mathrm{mL}$, próximo ao colo de cada planta. A reação do hospedeiro ao patógeno e sua avaliação foi realizada utilizando escala de nota de 1 (ausência de sintomas) a 5 (mais de $90 \%$ das raízes afetadas), com base na severidade da doença. Cultivares do tipo crespa e batavia foram todas resistentes. Cultivares do tipo americana e lisa apresentaram variação intervarietal quanto à reação da hospedeira ao patógeno.

Palavras-chave: Lactuca sativa L., Chalara elegans, podridão negra das raízes, tipos varietais de alface.

\section{ABSTRACT}

\section{Lettuce reaction to black root rot caused by Thielaviospsis basicola}

Lettuce is the most important leafy crop in Brazil. The varietal reaction of four lettuce types to lettuce black root rot (LBRR) caused by Thielaviopsis basicola at the juvenile stage were determined. The trial was carried out in controlled greenhouse conditions and arranged in completely randomized design, in a 37 x 2 (cultivars with and without inoculation) cheme with three replications. 30-day old seedlings were transplanted to styrofoam tray of 128 cells filled with $1 / 3$ of colonized substrate with 7,5 x $10^{5}$ conidia/g of substrate. After transplant, seedlings were reinoculated with a spore suspension with $2 \times 10^{6}$ conidia/mL poured next to the seedling stem. Host reaction to the pathogen and its evaluation were performed according to a severity scale from 1 (absence of symptoms) to 5 (more than $90 \%$ of rotted roots). Lettuce cultivars belonging to the loose leaf and batavia types were all resistant to LBRR. Cultivars of iceberg lettuce and butterhead types presented inter-varietal reactions being, some resistant and others susceptible.

Keywords: Lactuca sativa L., Chalara elegans, lettuce black root rot, lettuce types.

\section{(Recebido para publicação em 24 de janeiro de 2007; aceito em 7 de agosto de 2008)}

A alface é a hortaliça folhosa de maior importância no Brasil com uma área plantada de 35.000 ha. Seu cultivo é feito de maneira intensiva e geralmente praticada pela agricultura familiar, sendo responsável pela geração de cinco empregos diretos por hectare (Costa \& Sala, 2005).

Até meados da década de 1980, o padrão da alface consumida no país era alface lisa, tipo 'White Boston', que atualmente corresponde a $10 \%$ do mercado. Posteriormente, houve uma mudança da preferência de alface lisa para o segmento crespo, tipo 'Grand Rapids', que atualmente representa $70 \%$. A alface americana vem apresentando grande crescimento no Brasil, ocupando atualmente, mais de $15 \%$ do mercado (Costa \& Sala, 2005).

Em conseqüência de cultivos sucessivos de alface em áreas sem a rotação com outras culturas, doenças ocasionadas por patógenos habitantes do solo têm surgido. A murchadeira, causada pelo fungo Thielaviopsis basicola, sinanamorfo Chalara elegans Nag Raj \& Kendrick, vem limitando o plantio e expansão da alface americana e lisa, no cultivo de verão em algumas regiões de São Paulo.
As plantas infectadas pelo patógeno apresentam lesões amarronzadas no sistema radicular, num estágio inicial. Com o passar do tempo, as lesões tornam-se mais escuras. Normalmente, as raízes laterais são destruídas e as plantas passam a emitir novas raízes, com conseqüente redução do desenvolvimento da planta (O'Brien \& Davis, 2002). Nas horas mais quentes do dia ocorre a murcha da parte aérea, sintoma que é conhecido como murchadeira da alface.

Existe uma forte suspeita que $T$. basicola foi introduzido no Brasil através de turfa importada e contaminada e usado na formulação de substrato para produção de mudas (Teixeira-Yañez, 2005). Vários trabalhos têm demonstrado a importância da turfa como fonte de inóculo e disseminação da podridão negra das raízes em outros países. Na Flórida (EUA), a infecção de mudas de Citrus por T. basicola tem sido através de substrato à base de turfa contaminada com o patógeno (Graham \& Timmer, 1991) e o mesmo ocorrendo para alface, na Austrália, no início da década de 90 (O’Brien \& Davis, 1994).

Um fungo do gênero Thielaviopsis já foi constatado em nosso país, atacan- do plântulas de alface no estado do Rio de Janeiro (Silva et al., 1999). TeixeiraYañez (2005), avaliando a incidência do patógeno em plantios comerciais de alface no estado de São Paulo, obteve três isolados do patógeno a partir de mudas de alface contaminadas e produzidas com o uso de substrato. Embora a ocorrência de $T$. basicola já tenha sido relatada em alface nas condições brasileiras (Silva et al., 1999; Teixeira-Yañez, 2005), não existem dados quantitativos sobre danos causados pelo fungo.

Além da alface, o patógeno infecta outras culturas como algodão (King \& Presley, 1942), citros (Tsao \& Gundy, 1962), amendoim (Hsi, 1967), chicória (Prinsloo, 1986), quiabo (Silva et al., 1999), grão-de-bico (Bowden et al., 1985), pêssego, roseira e petúnia (Trebilco et al., 2002), soja (Mondal et al.; 2004), fumo (Yarwood, 1981), cenoura, ervilha, feijão e pepino (O'Brien \& Davis, 1994, 2002). O patógeno afeta mais de 33 famílias de plantas sendo relatado em mais de 46 países.

A utilização da técnica da solarização do solo (Teixeira-Yañez, 2005) e o uso de fungicidas (O’Brien \& Davis, 1994; 
Teixeira-Yañez, 2005) tem sido recomendado para o controle de $T$. basicola em alface, mas não há fungicidas registrados para seu controle no país.

Dessa forma, a melhor maneira de controle seria pelo uso de cultivares resistentes. Segundo O'Brien \& Davis (1994), avaliando a reação de cultivares de alface a T. basicola na Austrália, verificaram que 'Monaro', 'Kirralee', 'Centenário' e 'NKX030' foram resistentes enquanto que 'Classic', 'NKX029', 'Yatesdale' ' 'Buffalo' foram suscetíveis. No Brasil, Teixeira-Yañez (2005) concluíram que as cultivares do tipo lisa (Luisa, Elisa e Regina) foram suscetíveis, enquanto as do tipo crespa (Locarno, Vera e New Red Fire) foram resistentes, exceto 'Verônica'. Das cultivares do tipo americana, 'Invader', 'Classic' e 'Lucy Brown' foram suscetíveis, enquanto 'Warrior', 'Raider' e 'Mohawk' foram resistentes, segundo a mesma autora.

O cultivo da alface no Brasil é feito de maneira contínua na mesma área, sem rotação com até quatro safras sucessivas anuais. Este fato agrava a incidência de patógenos associados ao solo como é o caso de Thielaviopsis. Além do mais, cultiva-se várias dezenas de cultivares cuja reação ao patógeno é desconhecida. O conhecimento da reação varietal é importante para permitir a recomendação de determinadas cultivares em áreas de ocorrência do patógeno. Identificação de resistência contribui para uso em hibridação e posterior seleção visando a incorporação de genes de resistência a $T$. basicola no melhoramento genético de alface. O presente trabalho teve como objetivos determinar a reação das cultivares comerciais de alface de quatro tipos varietais a $T$. basicola.

\section{MATERIAL E MÉTODOS}

Os experimentos foram conduzidos no laboratório de Fitopatologia da USPESALQ em Piracicaba-SP, de 15/01/03 a $12 / 03 / 03$.

Usou-se o isolado $\mathrm{L}_{1}$ de Thielaviopsis basicola obtido a partir de plantas de alface lisa (cv. Elisa), provenientes de Paulínia-SP, por TeixeiraYañes (2005), para avaliar-se a reação de 37 cultivares de alface, sendo 18 do tipo americana, 9 do tipo crespa, 6 do tipo lisa e 4 do tipo batávia.

Para a multiplicação do inóculo usouse o meio de cultura proposto por Teixeira-
Yañez (2005) de BCA (batata-cenoura-ágar com $20 \mathrm{~g}$ de batata, $20 \mathrm{~g}$ de cenoura, $20 \mathrm{~g}$ de ágar e $1000 \mathrm{~mL}$ de água destilada) em placas de Petri e incubadas a $25^{\circ} \mathrm{C}$, sob escuro contínuo. Para obtenção de inóculo, adicionou-se $10 \mathrm{~mL}$ de água destilada às placas, 10 dias após incubação. Foi feita homogeneização do inóculo sobre a superfície do meio com auxílio de uma alça de vidro. Calibrou-se o número de conídios/ $\mathrm{mL}$ com auxílio de um hemacitômetro.

Mudas das cultivares de alfaces produzidas em bandejas de poliestireno expandido de 200 células foram transplantadas para bandejas de 128 células, com um terço de substrato (Plantmax ${ }^{\circledR} \mathrm{HA}$ ) colonizado com o isolado $\mathrm{L}_{1}$ na concentração de 7,5 x $10^{5}$ conídios/g de substrato. Após o transplante, $3 \mathrm{~mL}$ de uma suspensão de 2 x $10^{6}$ conídios $/ \mathrm{mL}$ foi adicionada à região do colo de cada muda. $\mathrm{O}$ substrato para produção de mudas e o colonizado foram previamente solarizados durante 72 h em coletor solar (Ghini, 1997). Para cada cultivar avaliada havia uma respectiva testemunha não inoculada. Conduziu-se o experimento em bandejas de 128 células, em casa-de-vegetação adotando-se irrigação intermitente por aspersão, acionado eletronicamente por um temporizador.

A escala de notas baseou-se no critério da severidade da doença, proposta por O’Brien \& Davis (1994): 1=ausência de sintomas; $2=$ traços de necrose nas radicelas; $3=$ menos de $50 \%$ das raízes necrosadas; $4=$ mais de $50 \%$ e menos de $90 \%$ das raízes necrosadas e $5=$ mais de $90 \%$ das raízes afetadas. Realizaram-se avaliações e leituras dos sintomas 22 dias após a inoculação, nas mudas mantidas em bandejas de 128 células.

O delineamento experimental foi inteiramente casualizado, em esquema fatorial $37 \times 2$ (trinta e sete cultivares de alface, com e sem inoculação), em três repetições, constituídas de seis plantas/ repetição. Plantas não inoculadas apresentaram nota 1 (ausência de sintoma) e não foram consideradas para análise estatística. A análise estatística dos dados foi feita pela comparação de médias pelo teste de Tukey $(\mathrm{a}=0,05)$ utilizando o programa SAS (SAS Institute, 1999).

\section{RESULTADOS E DISCUSSÃO}

As cultivares Elisa, Tainá, Empire, Invader, Luisa, Lady, SVR 1778, Lorca e Lucy Brown foram suscetíveis ao patógeno com nota média de severidade variando de 4,16 a 5, na fase juvenil. 'Sonoma' apresentou nota média 2,16 para severidade sendo estatisticamente semelhante às cultivares Stinger, Vera e Salinas 88, classificadas como resistentes a $T$. basicola. As demais cultivares testadas para reação ao patógeno mostraram-se resistentes (Tabela 1).

Todas as cultivares do tipo crespa e batávia foram resistentes ao patógeno. É importante destacar que, no Brasil, a alface crespa representa $70 \%$ do mercado desta folhosa (Costa \& Sala, 2005), sendo 'Vera' e 'Verônica' as cultivares mais plantadas e líderes de vendas. Teixeira-Yañez (2005) avaliando a patogenicidade in vitro de $T$. basicola (isolado $\mathrm{L}_{1}$ ) das cultivares de alface a $21^{\circ} \mathrm{C}$, verificou que as cultivares do tipo crespa foram resistentes, com exceção de 'Verônica' que comportou-se como suscetível, o que não foi observado no presente trabalho, pois a mesma mostrou-se resistente. Entretanto, segundo a mesma autora, a drástica metodologia de inoculação in vitro e estágio juvenil da planta não permitiram a expressão da resistência ao patógeno, não obtendo correlação dos resultados de inoculação in vitro com aqueles obtidos nos testes in vivo.

Segundo Prinsloo et al. (1993) e Sala et al. (2004) as cultivares de chicória do tipo crespa, conhecida como frisée, foram resistentes a $T$. basicola, da mesma forma que todas as cultivares de alface do tipo crespa (Tabela 1). Diante desse resultado, é possível que o gene que confere resistência a $T$. basicola esteja ligado ao gene que confere crespecidade foliar nas cultivares de alface e chicória. Sala et al. (2006) relataram que a resistência de alface a $T$. basicola, nas cultivares estudadas, é controlada por um gene dominante, denominado $T b$.

As cultivares de alface do tipo lisa e americana apresentaram variação intervarietal quanto à reação ao patógeno. As cultivares do tipo lisa 'Elisa' e 'Luisa' foram suscetíveis estando de acordo com os resultados obtidos por TeixeiraYañez (2005). Esses resultados confirmam a limitação dessas cultivares em áreas com histórico da doença.

As cultivares do tipo americana 'Stinger', 'Salinas 88', 'Niner', 'Rubete', 'Mohawk', 'PRS 113', 'PRS 115', 'Raider' e 'Yuri' foram resistentes, enquanto que 'Tainá', 'Empire', 'Invader', 'Lady', 'SVR 1778', 'Lorca' e 'Lucy 
Brown' foram suscetíveis (Tabela 1). A cultivar Lucy Brown tem sido a alface americana mais plantada no Brasil por mais de uma década, graças à sua extraordinária adaptabilidade de cultivo no verão (Costa \& Sala, 2005). Entretanto, seu cultivo em áreas com incidência de $T$. basicola vem sendo limitado devido à sua suscetibilidade ao patógeno. Existe a demanda de uma cultivar de alface americana adaptada ao cultivo de verão e com resistência à murcha causada por T. basicola .

Os resultados observados da reação das cultivares de alface a T. basicola, na fase juvenil, confirmam suas reações em condições de campo com alta incidência da murchadeira. Deste modo, os resultados evidenciam a validade do controle genético. Identificar cultivares de alface resistentes ao patógeno poderá ser importante contribuição para o melhoramento desta folhosa visando resistência a $T$. basicola.

\section{REFERÊNCIAS}

BOWDEN RL; WIESE MV; CROCK JE; AULD DL. 1985. Root rot of chickpeas and lentils caused by Thielaviopsis basicola. Plant Disease 69: 1089-1091.

COSTA CP; SALA FC. 2005. A evolução da alfacicultura brasileira. Horticultura Brasileira. 23: 1(artigo de capa).

GHINI R. 1997. Desinfestação do solo com o uso de energia solar: solarização e coletor solar. Jaguariúna: EMBRAPA-CNPMA, 29 p. (Circular Técnica, $\mathrm{n}^{\circ} 1$ ).

GRAHAN JH; TIMMER NH. 1991. Peat-based media as a source of Thielaviopsis basicola causing black root rot on citrus seedlings. Plant Disease 75: 1246-1249.

HIS DCH. 1967. Relationship between crop sequences and several diseases of Valencia peanuts. Phytopathology 57: 461.

KING CJ; PRESLEY JT. 1942. A root rot of cotton caused by Thielaviopsis basicola. Phytopathology 32: 752-761.

MONDAL AH; NEHL DB; ALLEN SJ. 2004. First report $\mathrm{f}$ Thielaviopsis basicola on soybean in Australia. Australasian Plant Pathology 33: 451-452.

O'BRIEN RG; DAVIS RD. 1994. Lettuce black root rot - a disease caused by Chalara elegans. Australasian Plant Pathology 23: 106-111.

O'BRIEN RG; DAVIS RD. 2002, 20 de março. Black root rot of lettuce - dpi note. Disponível em http://www.dpi.qld.gov.au/horticulture/ 4759.html.

PRINSLOO GC. 1986. Black root rot of chicory in South Africa. Phytophylactica 18: 225-226.

PRINSLOO GC; BAARD SW; FERREIRAJF. 1993. Resistance of chicory and endive to black root rot and the effect of their exudates on Thielaviopsis basicola. Phytophylactica 25: 107-114.

SALA FC; COSTA CP; TEIXEIRA-YAÑEZ LDD; BLAT SF. 2004. Reação de chicória a murchadeira (Thielaviopis basicola). Summa Phytopathologica 30: 1.

Tabela 1. Reação de cultivares de alface a Thielaviopsis basicola (Lettuce cultivars reaction to Thielaviopsis basicola). Piracicaba-SP, 2003.

\begin{tabular}{|c|c|c|c|}
\hline Cultivares & Tipo & \multicolumn{2}{|c|}{ Notas $^{1}$} \\
\hline Elisa & Lisa & \multicolumn{2}{|l|}{$5,00 \mathrm{a}$} \\
\hline Tainá & Americana & \multicolumn{2}{|c|}{$4,94 \mathrm{a}$} \\
\hline Empire & Americana & \multicolumn{2}{|c|}{$4,77 \mathrm{a}$} \\
\hline Invader & Americana & \multicolumn{2}{|c|}{4,66 a } \\
\hline Luisa & Lisa & \multicolumn{2}{|l|}{$4,55 \mathrm{a}$} \\
\hline Lady & Americana & \multicolumn{2}{|c|}{$4,55 \mathrm{a}$} \\
\hline SVR 1778 & Americana & \multicolumn{2}{|c|}{$4,44 \mathrm{a}$} \\
\hline Lorca & Americana & \multicolumn{2}{|c|}{$4,21 \mathrm{a}$} \\
\hline Lucy Brown & Americana & \\
\hline Sonoma & Americana & \multicolumn{2}{|c|}{$2,16 \quad b$} \\
\hline Stinger & Americana & \multicolumn{2}{|c|}{$1,73 \mathrm{bc}$} \\
\hline Vera & Crespa & \multicolumn{2}{|c|}{$1,55 \mathrm{bcd}$} \\
\hline Salinas 88 & Americana & \multicolumn{2}{|c|}{1,44 bcde } \\
\hline Niner & Americana & \multicolumn{2}{|c|}{1,37 cde } \\
\hline Rubete & Americana & \multicolumn{2}{|c|}{1,32 cde } \\
\hline Mohawk & Americana & \multicolumn{2}{|c|}{$1,27 \quad \mathrm{cde}$} \\
\hline PRS 113 & Americana & \multicolumn{2}{|c|}{1,27 cde } \\
\hline PRS 115 & Americana & \multicolumn{2}{|c|}{$1,22 \mathrm{~cd} \epsilon$} \\
\hline Raider & Americana & \multicolumn{2}{|c|}{$1,16 \mathrm{~cd} \epsilon$} \\
\hline Yuri & Americana & \multicolumn{2}{|c|}{1,16 cde } \\
\hline EX2622 & Lisa & \multicolumn{2}{|c|}{1,16 cde } \\
\hline Simpson Elite & Crespa & \multicolumn{2}{|c|}{1,16 cde } \\
\hline Gorga & Batávia & \multicolumn{2}{|c|}{$1,10 \quad \mathrm{de}$} \\
\hline Batavia Pierre Benite & Batávia & \multicolumn{2}{|c|}{1,10 de } \\
\hline PRS 261 & Americana & \multicolumn{2}{|c|}{$1,05 \mathrm{de}$} \\
\hline Mariane & Crespa & \multicolumn{2}{|c|}{$1,05 \mathrm{de}$} \\
\hline Brisa & Crespa & \multicolumn{2}{|c|}{$1,05 \mathrm{de}$} \\
\hline Ninja & Lisa & 1,05 & de \\
\hline Verônica & Crespa & 1,05 & de \\
\hline Korean Leaf & Crespa & 1,05 & de \\
\hline Locarno & Crespa & 1,00 & $\mathrm{e}$ \\
\hline Letícia & Lisa & 1,00 & $\mathrm{e}$ \\
\hline Batavia 301397 & Batávia & 1,00 & $\mathrm{e}$ \\
\hline La Brilliante & Batávia & 1,00 & $\mathrm{e}$ \\
\hline Banchu New Red Fire & Crespa & 1,00 & $\mathrm{e}$ \\
\hline Green Day & Crespa & 1,00 & $\mathrm{e}$ \\
\hline Tinto & Lisa & 1,00 & $\mathrm{e}$ \\
\hline$\overline{C V}(\%)$ & & 25,41 & \\
\hline
\end{tabular}

Médias seguidas de mesma letra não diferem entre si pelo teste de Tukey a 0,05; ${ }^{1}$ Dados originais. Para efeito de análise os dados foram transformados em log de $\mathrm{x}$ na base 10 (Means followed by the same letter do not differ, Tukey's test, $\mathrm{p}<0.05$. 1Original data transformed in $\log \mathrm{x} 10$ ).

SALA FC. 2006. Reação de alface (Lactuca sativa L.) a Thielaviopsis basicola (Berk. \& Broome) Ferraris. Piracicaba: USP-ESALQ. 97p. (Tese doutorado).

SAS INSTITUTE. 1999. SAS/STAT User's Guide, Version 6, Cary.

SILVA AMS; AKIBA F; CARVALHO AO; RIBEIRO RLD; ARAÚJO JSP. 1999. Podridão negra de raízes de quiabeiro e alface incitada por Thielaviopsis spp. In: $32^{\circ}$ CONGRESSO BRASILEIRO DE FITOPATOLOGIA, 4. Resumos... Brasília: SBF. (CD-ROM).

TEIXEIRA-YAÑEZLDD. 2005. Resistência genética, fungicidas e solarização para o controle de Thielaviopsis basicola (Berk. \& Broome) Ferraris na cultura de alface (Lactuca sativa $L$.). Piracicaba: USP-ESALQ. 103p. (Tese doutorado).
TREBILCO E; HOWELL J; FORSBERG L; BODMAN K. Beware of Chalara elegans black root rot. Disponível em http:// www.ngia.com.au/np/99_13/99_13.html. Acessado em 25 de março de 2002.

TSAO PH; GUNDY SD. 1962. Thielaviopsis basicola as a citrus root pathogen. Phytopathology 52: 781-786.

YARWOOD CE. 1981. Occurrence of Chalara elegans. Mycologia 73: 524-530. 